\title{
Existence of Periodic Fixed Point Theorems in the Setting of Generalized Quasi-Metric Spaces
}

\author{
Chi-Ming Chen, ${ }^{1}$ Erdal Karapınar, ${ }^{2,3}$ and Vladimir Rakočevic ${ }^{4}$ \\ ${ }^{1}$ Department of Applied Mathematics, National Hsinchu University of Education, Taiwan \\ ${ }^{2}$ Atılım University Department of Mathematics, Incek, 06586 Ankara, Turkey \\ ${ }^{3}$ Nonlinear Analysis and Applied Mathematics Research Group (NAAM), King Abdulaziz University, Jeddah, Saudi Arabia \\ ${ }^{4}$ Faculty of Sciences and Mathematics, University of Nis, Visegradska 33, 18000 Nis, Serbia
}

Correspondence should be addressed to Chi-Ming Chen; ming@mail.nhcue.edu.tw

Received 9 July 2014; Accepted 16 August 2014; Published 26 August 2014

Academic Editor: Lai-Jiu Lin

Copyright (C) 2014 Chi-Ming Chen et al. This is an open access article distributed under the Creative Commons Attribution License, which permits unrestricted use, distribution, and reproduction in any medium, provided the original work is properly cited.

We introduce the notions of $(\alpha-\phi-\psi)$-weaker Meir-Keeler contractive mappings and $(\alpha-\varphi)$-stronger Meir-Keeler contractive mappings. We discuss the existence of periodic points in the setting of generalized quasi-metric spaces. Our results improve, extend, and generalize several results in the literature.

\section{Introduction and Preliminaries}

Very recently, Lin et al. [1] introduced the notion of generalized quasi-metric inspired from the notion of generalized metric, defined by Branciari [2]. It is a very well-known fact that the concept of generalized metric can be derived from the definition of metric by replacing the triangle inequality with a weaker condition, namely, quadrilateral inequality. In spite of the analogy between the definitions of metric and generalized metric, the topological structure of these spaces is completely different. It was proved that the topologies of these two spaces are incomparable [3].

In what follows that we recall the basic definitions and results on the topics for the sake of completeness. Throughout the paper, the symbols $\mathbb{R}, \mathbb{N}$, and $\mathbb{N}_{0}$ denote the real numbers, the natural numbers, and the positive integers, respectively.

A quite natural generalization of the notion of a metric was introduced by Branciari [2] in 2000 by replacing the triangle inequality assumption of a metric with a weaker condition, quadrilateral inequality.

Definition 1 (see [2]). Let $X$ be a nonempty set and let $d$ : $X \times X \rightarrow[0, \infty)$ be a mapping such that for all $x, y \in X$ and for all distinct point $u, v \in X$ each of them different from $x$ and $y$, one has

(d1) $d(x, y)=0$ if and only if $x=y$; (d2) $d(x, y)=d(y, x)$;

(d3) $d(x, y) \leq d(x, u)+d(u, v)+d(v, y)$ (quadrilateral inequality).

Then $(X, d)$ is called a generalized metric space (or shortly g.m.s).

The following example illustrates that not every generalized metric on a set $X$ is a metric on $X$.

Example 2 (see e.g. $[1,4]$ ). Let $X=\{t, 2 t, 3 t, 4 t, 5 t\}$ with $t>0$ is a constant, and we define $d: X \times X \rightarrow[0, \infty)$ by

(1) $d(x, x)=0$, for all $x \in X$;

(2) $d(x, y)=d(y, x)$, for all $x, y \in X$;

(3) $d(t, 2 t)=3 \gamma$;

(4) $d(t, 3 t)=d(2 t, 3 t)=\gamma$;

(5) $d(t, 4 t)=d(2 t, 4 t)=d(3 t, 4 t)=2 \gamma$;

(6) $d(t, 5 t)=d(2 t, 5 t)=d(3 t, 5 t)=d(4 t, 5 t)=(3 / 2) \gamma$,

where $\gamma>0$ is a constant. Then $(X, d)$ is a generalized metric space, but it is not a metric space, because

$$
d(t, 2 t)=3 \gamma>d(t, 3 t)+d(3 t, 2 t)=2 \gamma .
$$


Now, we will mention that some standard properties can not be possesed by generalized metric: more precisely,

(P1) open ball need not be open set,

(P2) a convergent sequence in generalized metric space needs not to be Cauchy,

(P3) generalized metric needs not to be continuous,

(P4) generalized metric space needs not to be Hausdorff, and hence the uniqueness of limits can not be guaranteed.

Several authors noticed these weak points of the generalized metric space and inserted some additional assumptions to get the analog of celebrated fixed point theorems in the context of generalized metric space. In particular, generalized metric space assumed Hausdorff. Later, several authors proved that this assumption is superfluous; see for example [5-9].

Example 3 (see [10], Example 1.1). Let $X=A \cup B$ where $A=$ $\{0,2\}$ and $A=\{1 / n: n \in \mathbb{N}\}$. Define $d: X \times X \rightarrow[0, \infty)$ in the following way:

$$
d(x, y)= \begin{cases}0, & \text { if } x=y \\ 1, & \text { if } x \neq y, \quad[\{x, y\} \subset A \text { or }\{x, y\} \subset B] \\ y, & \text { if } x \in A, y \in B .\end{cases}
$$

Notice that $d(a, b)=d(b, a)=b$ whenever $a \in A$ and $b \in B$. Furthermore, $(X, d)$ is a complete generalized metric space. Clearly, we have (P1)-(P4). Indeed, the sequence $\{1 / n: n \in$ $\mathbb{N}$ \} converges to both 0 and 2 . There is no $r>0$ such that $B_{r}(0) \cap B_{r}(2)=\emptyset$ and hence it is not Hausdorff. It is clear that the ball $B_{2 / 3}(1 / 3)=\{0,1 / 3,2\}$ since there is no $r>0$ such that $B_{r}(=) \subset B_{2 / 3}(1 / 3)$; that is, open balls may not be an open set. The function $d$ is not continuous since $\lim _{n \rightarrow \infty} d(1 / n, 1 / 2) \neq$ $d(0,1 / 2)$ although $\lim _{n \rightarrow \infty}(1 / n)=0$. For more details see, for example, $[4,8,10]$.

Regarding the weakness of the topology of generalized metric space, mentioned above, the authors add some additional conditions to get the analog of existing fixed point results in the literature; see, for example, [11-17].

The following is the definition of the notion of generalized quasi-metric space defined by Lin et al. [1].

Definition 4. Let $X$ be a nonempty set and let $d: X \times X \rightarrow$ $[0, \infty)$ be a mapping such that, for all $x, y \in X$ and for all distinct point $u, v \in X$ each of them different from $x$ and $y$, one has

(i) $d(x, y)=0$ if and only if $x=y$;

(ii) $d(x, y) \leq d(x, u)+d(u, v)+d(v, y)$.

Then $(X, d)$ is called a generalized quasi-metric space (or shortly g.q.m.s).

It is evident that any generalized metric space is a generalized quasi-metric space, but the converse is not true in general. We give an example to show that not every generalized quasi-metric on a set $X$ is a generalized metric on $X$.

Example 5 (see [1]). Let $X=\{t, 2 t, 3 t, 4 t, 5 t\}$ with $t>0$ being a constant, and we define $d: X \times X \rightarrow[0, \infty)$ by

(1) $d(x, x)=0$, for all $x \in X$;

(2) $d(t, 2 t)=d(2 t, t)=3 \gamma$;

(3) $d(t, 3 t)=d(2 t, 3 t)=d(3 t, t)=d(3 t, 2 t)=\gamma$;

(4) $d(t, 4 t)=d(2 t, 4 t)=d(3 t, 4 t)=d(4 t, t)=d(4 t, 2 t)=$ $d(4 t, 3 t)=2 \gamma$

(5) $d(t, 5 t)=d(2 t, 5 t)=d(3 t, 5 t)=d(4 t, 5 t)=(3 / 2) \gamma$;

(6) $d(5 t, t)=d(5 t, 2 t)=d(5 t, 3 t)=d(5 t, 4 t)=(5 / 4) \gamma$,

where $\gamma>0$ is a constant. Then $(X, d)$ is a generalized quasimetric space, but it is not a generalized metric space, because

$$
d(t, 5 t)=\frac{3}{2} \gamma \neq d(5 t, t)=\frac{5}{4} \gamma .
$$

We next give the definitions of convergence and completeness on generalized quasi-metric spaces.

Definition 6 (see [1]). Let $(X, d)$ be a g.q.m.s, and let $\left\{x_{n}\right\}$ be a sequence in $X$ and $x \in X$. We say that $\left\{x_{n}\right\}$ is g.q.m.s convergent to $x$ if and only if

$$
\lim _{n \rightarrow \infty} d\left(x_{n}, x\right)=\lim _{n \rightarrow \infty} d\left(x, x_{n}\right)=0 .
$$

Definition 7 (see [1]). Let $(X, d)$ be a g.q.m.s and let $\left\{x_{n}\right\}$ be a sequence in $X$. We say that $\left\{x_{n}\right\}$ is left-Cauchy if and only if for every $\varepsilon>0$ there exits $k \in \mathbb{N}$ such that $d\left(x_{n}, x_{m}\right)<\varepsilon$ for all $n \geq m>k$.

Definition 8 (see [1]). Let $(X, d)$ be a g.q.m.s and let $\left\{x_{n}\right\}$ be a sequence in $X$. We say that $\left\{x_{n}\right\}$ is right-Cauchy if and only if for every $\varepsilon>0$ there exits $k \in \mathbb{N}$ such that $d\left(x_{n}, x_{m}\right)<\varepsilon$ for all $m \geq n>k$.

Definition 9 (see [1]). Let $(X, d)$ be a g.q.m.s and let $\left\{x_{n}\right\}$ be a sequence in $X$. We say that $\left\{x_{n}\right\}$ is Cauchy if and only if for every $\varepsilon>0$ there exits $k \in \mathbb{N}$ such that $d\left(x_{n}, x_{m}\right)<\varepsilon$ for all $m, n>k$.

Remark 10. A sequence $\left\{x_{n}\right\}$ in a g.q.m.s is Cauchy if and only if it is left-Cauchy and right-Cauchy.

Definition 11 (see [1]). Let $(X, d)$ be a g.q.m.s. We say that

(1) $(X, d)$ is left-complete if and only if each left-Cauchy sequence in $X$ is convergent;

(2) $(X, d)$ is right-complete if and only if each rightCauchy sequence in $X$ is convergent;

(3) $(X, d)$ is complete if and only if each Cauchy sequence in $X$ is convergent.

In this paper, we examine the existence of $(\alpha-\psi)$ contractive mappings in the context of generalized quasimetric space without the assumption of being a Hausdorff. Consequently, our results extend, improve, and generalize several results in the literature. 


\section{Periodic Points of Weaker Meir-Keeler Contractive Mappings}

In this section, we recall the weaker Meir-Keeler function and a weaker Meir-Keeler function, as follows.

Definition 12 (see [18]). A function $\psi:[0, \infty) \rightarrow[0, \infty)$ is said to be a Meir-Keeler type function, if, for each $\eta \in[0, \infty)$, there exists $\delta>0$ such that for $t \in[0, \infty)$ with $\eta \leq t<\eta+\delta$, we have $\psi(t)<\eta$.

Definition 13 . We call $\phi:[0, \infty) \rightarrow[0, \infty)$ a weaker MeirKeeler function if the function $\phi$ satisfies the following condition:

$$
\begin{array}{r}
\forall \eta>0, \quad \exists \delta>0, \quad \forall t \in[0, \infty), \\
\left(\eta \leq t<\delta+\eta \Longrightarrow \exists n_{0} \in \mathbb{N}, \phi(t)^{n_{0}}<\eta\right) .
\end{array}
$$

In the sequel, we need the following classes of auxiliary functions. Let $\Phi$ denote the set of the nondecreasing functions $\phi:[0, \infty) \rightarrow[0, \infty)$ satisfying the following conditions:

$\left(\phi_{1}\right) \phi:[0, \infty) \rightarrow[0, \infty)$ is a weaker Meir-Keeler function;

$\left(\phi_{2}\right) \phi(t)>0$ for $t>0$ and $\phi(0)=0$;

$\left(\phi_{3}\right)$ for all $t \in(0, \infty),\left\{\phi^{n}(t)\right\}_{n \in \mathbb{N}}$ is decreasing;

$\left(\phi_{4}\right)$ for $t>0$, if $\lim _{n \rightarrow \infty} \phi^{n}(t)=0$, then $\lim _{n \rightarrow \infty} \sum_{i=n}^{m} \phi^{i}(t)=0$, where $m>n$.

Furthermore, let $\Psi$ denote the set of functions $\psi$ : $[0, \infty) \rightarrow[0, \infty)$ satisfying the following conditions:

$\left(\psi_{1}\right) \psi$ is continuous;

$\left(\psi_{2}\right) \psi(t)>0$ for $t>0$ and $\psi(0)=0$.

The following lemma plays a crucial role in the proof of the main result that were inspired from $[5,8]$, proved first in [4].

Lemma 14 (see $[4])$. Let $(X, d)$ be a generalized quasi-metric space and let $\left\{x_{n}\right\}$ be a Cauchy sequence in $X$ such that $x_{m} \neq x_{n}$ whenever $m \neq n$. Then the sequence $\left\{x_{n}\right\}$ can converge to at most one point.

Proof. Given $\varepsilon>0$. Since $\left\{x_{n}\right\}$ is a Cauchy sequence, there exists $k_{0} \in \mathbb{N}$ such that

$$
d\left(x_{n}, x_{m}\right)<\varepsilon, \quad \forall m, n>k_{0} .
$$

We use the method of Reductio ad absurdum. Suppose, on the contrary, that there exist two distinct points $x$ and $y$ in $X$ such that the sequence $\left\{x_{n}\right\}$ converges to $x$ and $y$, that is,

$$
\begin{aligned}
& \lim _{n \rightarrow \infty} d\left(x_{n}, x\right)=\lim _{n \rightarrow \infty} d\left(x, x_{n}\right)=0, \\
& \lim _{n \rightarrow \infty} d\left(x_{n}, y\right)=\lim _{n \rightarrow \infty} d\left(y, x_{n}\right)=0 .
\end{aligned}
$$

By assumption for any $n \in \mathbb{N}, x_{n} \neq x_{m}$ and since $x \neq y$, there exists $k_{1} \in \mathbb{N}$ such that $x_{n} \neq x$ and $x_{n} \neq y$ for any $n>k_{1} \geq k_{0}$. Due to quadrilateral inequality, we have

$$
d(x, y) \leq d\left(x, x_{n}\right)+d\left(x_{n}, x_{m}\right)+d\left(x_{m}, y\right) .
$$

Letting $n, m \rightarrow \infty$, we can obtain that $d(x, y)=0$ by regarding (6) and (7). Hence, we get $x=y$ which is a contradiction.

In this study, we also recall the following notions of $\alpha$ admissible mappings.

Definition 15 (see [19]). Let $f: X \rightarrow X$ be a self-mapping of a set $X$ and $\alpha: X \times X \rightarrow \mathbb{R}^{+}$. Then $f$ is called a $\alpha$-admissible if

$$
x, y \in X, \quad \alpha(x, y) \geq 1 \Longrightarrow \alpha(f x, f y) \geq 1 .
$$

We now introduce the notion of $(\alpha-\phi-\psi)$-weaker MeirKeeler contractive mappings in the following way.

Definition 16. Let $(X, d)$ be a g.q.m.s, let $\alpha: X \times X \rightarrow \mathbb{R}^{+}$, and let $f: X \rightarrow X$ be a function satisfying

$$
\alpha(x, y) d(f x, f y) \leq \phi(d(x, y))-\psi(d(x, y)),
$$

for all $x, y \in X$. Then $f$ is said to be a $(\alpha-\phi-\psi)$-weaker Meir-Keeler contractive mapping.

We state two main periodic point theorems of $(\alpha-\phi-\psi)$ weaker Meir-Keeler contractive mapping, as follow.

Theorem 17. Let $(X, d)$ be a complete g.q.m.s, and let $\alpha: X \times$ $X \rightarrow \mathbb{R}^{+}$. Suppose $f$ is a $(\alpha-\phi-\psi)$-weaker Meir-Keeler contractive mapping which satisfies

(i) $f$ is $\alpha$-admissible;

(ii) there exists $x_{0} \in X$ such that $\alpha\left(x_{0}, f x_{0}\right) \geq 1$, $\alpha\left(f x_{0}, x_{0}\right) \geq 1$ and $\alpha\left(x_{0}, f^{2} x_{0}\right) \geq 1, \alpha\left(f^{2} x_{0}, x_{0}\right) \geq 1$;

(iii) $f$ is continuous.

Then $f$ has a periodic point in $X$.

Proof. Regarding the assumption (ii) of theorem, we let $x_{0} \in$ $X$ be an arbitrary point such that $\alpha\left(x_{0}, f x_{0}\right) \geq 1$ and $\alpha\left(x_{0}, f x_{0}\right) \geq 1$. We will construct a sequence $\left\{x_{n}\right\}$ in $X$ by $x_{n+1}=f x_{n}=f^{n+1} x_{0}$ for all $n \geq 0$. If we have $x_{n_{0}}=x_{n_{0}+1}$ for some $n_{0}$, then $u=x_{n_{0}}$ is a fixed point of $f$. Hence, for the rest of the proof, we presume that

$$
x_{n} \neq x_{n+1} \quad \forall n .
$$

Since $f$ is $\alpha$-admissible, we have

$$
\begin{aligned}
& \alpha\left(x_{0}, x_{1}\right)=\alpha\left(x_{0}, f x_{0}\right) \geq 1 \\
& \Longrightarrow \alpha\left(f x_{0}, f x_{1}\right)=\alpha\left(x_{1}, x_{2}\right) \geq 1 .
\end{aligned}
$$

Utilizing the expression above, we obtain that

$$
\alpha\left(x_{n}, x_{n+1}\right) \geq 1, \quad \forall n=0,1, \ldots
$$


By repeating the same steps with starting with the assumption $\alpha\left(x_{1}, x_{0}\right)=\alpha\left(f x_{0}, x_{0}\right) \geq 1$, we conclude that

$$
\alpha\left(x_{n+1}, x_{n}\right) \geq 1, \quad \forall n=0,1, \ldots
$$

In a similar way, we derive that

$$
\begin{aligned}
& \alpha\left(x_{0}, x_{2}\right)=\alpha\left(x_{0}, f^{2} x_{0}\right) \geq 1 \\
& \Longrightarrow \alpha\left(f x_{0}, f x_{2}\right)=\alpha\left(x_{1}, x_{3}\right) \geq 1 .
\end{aligned}
$$

Recursively, we get that

$$
\alpha\left(x_{n}, x_{n+2}\right) \geq 1, \quad \forall n=0,1, \ldots .
$$

Analogously, we can easily derive that

$$
\alpha\left(x_{n+2}, x_{n}\right) \geq 1, \quad \forall n=0,1, \ldots
$$

In the sequel, we prove that the sequence $\left\{x_{n}\right\}$ is Cauchy; that is, $\left\{x_{n}\right\}$ is both right-Cauchy and left-Cauchy.

Step 1. We will prove that

$$
\lim _{n \rightarrow \infty} d\left(x_{n}, x_{n+1}\right)=0 \text {. }
$$

Since $f$ is a $(\alpha-\phi-\psi)$-weaker Meir-Keeler contractive mapping, we have that, for each $n \in \mathbb{N} \cup\{0\}$,

$$
\begin{aligned}
d\left(x_{n}, x_{n+1}\right) & =d\left(f x_{n-1}, f x_{n}\right) \\
& \leq \alpha\left(x_{n-1}, x_{n}\right) d\left(f x_{n-1}, f x_{n}\right) \\
& \leq \phi\left(d\left(x_{n-1}, x_{n}\right)\right)-\psi\left(d\left(x_{n-1}, x_{n}\right)\right) \\
& \leq \phi\left(d\left(x_{n-1}, x_{n}\right)\right) .
\end{aligned}
$$

Since $\phi$ is nondecreasing, by iteration, we derive the following inequality:

$$
d\left(x_{n}, x_{n+1}\right) \leq \phi^{n}\left(d\left(x_{0}, x_{1}\right)\right) .
$$

Due to fact that $\phi$ is weak Meir-Keeler function, we find that

$$
\lim _{n \rightarrow \infty} d\left(x_{n}, x_{n+1}\right)=0 .
$$

Since $\left\{\phi^{n}\left(d\left(x_{0}, x_{1}\right)\right)\right\}_{n \in \mathbb{N}}$ is decreasing, it must converge to some $\eta \geq 0$. We claim that $\eta=0$. Suppose, on the contrary, that $\eta>0$. Then by the definition of weaker Meir-Keeler function $\phi$, corresponding to the given $\eta$, there exists $\delta>0$ such that for $x_{0}, x_{1} \in X$ with $\eta \leq d\left(x_{0}, x_{1}\right)<\delta+\eta$, and $n_{0} \in \mathbb{N}$ such that $\phi^{n_{0}}\left(d\left(x_{0}, x_{1}\right)\right)<\eta$. Since $\lim _{n \rightarrow \infty} \phi^{n}\left(d\left(x_{0}, x_{1}\right)\right)=\eta$, there exists $p_{0} \in \mathbb{N}$ such that $\eta \leq \phi^{p}\left(d\left(x_{0}, x_{1}\right)\right)<\delta+\eta$, for all $p \geq p_{0}$. Thus, we conclude that $\phi^{p_{0}+n_{0}}\left(d\left(x_{0}, x_{1}\right)\right)<\eta$, which is a contradiction. Therefore $\lim _{n \rightarrow \infty} \phi^{n}\left(d\left(x_{0}, x_{1}\right)\right)=0$, that is,

$$
\lim _{n \rightarrow \infty} d\left(x_{n}, x_{n+1}\right)=0
$$

Step 2. We will prove that

$$
\lim _{n \rightarrow \infty} d\left(x_{n}, x_{n+2}\right)=0 .
$$

Since $f$ is a $(\alpha-\phi-\psi)$-weaker Meir-Keeler contractive mapping, we have that, for each $n \in \mathbb{N} \cup\{0\}$,

$$
\begin{aligned}
d\left(x_{n}, x_{n+2}\right) & =d\left(f x_{n-1}, f x_{n+1}\right) \\
& \leq \alpha\left(x_{n-1}, x_{n+1}\right) d\left(f x_{n-1}, f x_{n+1}\right)
\end{aligned}
$$

$$
\begin{aligned}
& \leq \phi\left(d\left(x_{n-1}, x_{n+1}\right)\right)-\psi\left(d\left(x_{n-1}, x_{n+1}\right)\right) \\
& \leq \phi\left(d\left(x_{n-1}, x_{n+1}\right)\right) .
\end{aligned}
$$

Inductively, we find that

$$
d\left(x_{n}, x_{n+2}\right) \leq \phi^{n}\left(d\left(x_{0}, x_{2}\right)\right),
$$

by using the fact that $\phi$ is nondecreasing. Since $\left\{\phi^{n}\left(d\left(x_{0}, x_{2}\right)\right)\right\}_{n \in \mathbb{N}}$ is decreasing, it must converge to some $\eta \geq 0$. We claim that $\eta=0$. Suppose, on the contrary, that $\eta>0$. Then by the definition of weaker Meir-Keeler function $\phi$, corresponding to the given $\eta$, there exists $\delta>0$ such that for $x_{0}, x_{2} \in X$ with $\eta \leq d\left(x_{0}, x_{2}\right)<\delta+\eta$, and $n_{0} \in \mathbb{N}$ such that $\phi^{n_{0}}\left(d\left(x_{0}, x_{2}\right)\right)<\eta$. Since $\lim _{n \rightarrow \infty} \phi^{n}\left(\varphi\left(d\left(x_{0}, x_{2}\right)\right)\right)=\eta$, there exists $p_{0} \in \mathbb{N}$ such that $\eta \leq \phi^{p}\left(d\left(x_{0}, x_{2}\right)\right)<\delta+\eta$, for all $p \geq p_{0}$. Thus, we conclude that $\phi^{p_{0}+n_{0}}\left(d\left(x_{0}, x_{2}\right)\right)<\eta$, which is a contradiction. Therefore $\lim _{n \rightarrow \infty} \phi^{n}\left(d\left(x_{0}, x_{2}\right)\right)=0$; that is,

$$
\lim _{n \rightarrow \infty} d\left(x_{n}, x_{n+2}\right)=0
$$

Step 3. We will prove that the sequence $\left\{x_{n}\right\}$ is right-Cauchy by standard technique. For this purpose, it is sufficient to examine two cases.

Case (I). Suppose that $k>2$ and $k$ is odd. Let $k=2 m+1$, $k \geq 1$. Then, by using the quadrilateral inequality, we have

$$
\begin{aligned}
d\left(x_{n}, x_{n+k}\right)= & d\left(x_{n}, x_{n+2 m+1}\right) \\
\leq & d\left(x_{n}, x_{n+1}\right)+d\left(x_{n+1}, x_{n+2}\right) \\
& +d\left(x_{n+2}, x_{n+2 m+1}\right) \\
\leq & d\left(x_{n}, x_{n+1}\right)+d\left(x_{n+1}, x_{n+2}\right) \\
& +d\left(x_{n+2}, x_{n+3}\right)+\cdots+d\left(x_{n+2 m}, x_{n+2 m+1}\right) \\
= & d\left(f x_{n-1}, f x_{n}\right)+d\left(f x_{n}, f x_{n+1}\right) \\
& +d\left(f x_{n+1}, f x_{n+2}\right)+\cdots \\
& +d\left(f x_{n+2 m-1}, x_{n+2 m}\right) \\
\leq & \alpha\left(x_{n-1}, x_{n}\right) d\left(f x_{n-1}, f x_{n}\right)+\alpha\left(x_{n}, x_{n+1}\right) \\
& \times d\left(f x_{n}, f x_{n+1}\right)+\alpha\left(x_{n+1}, x_{n+2}\right) \\
& \times d\left(f x_{n+1}, f x_{n+2}\right)+\cdots \\
& +\alpha\left(x_{n+2 m-1}, x_{n+2 m}\right) d\left(f x_{n+2 m-1}, x_{n+2 m}\right) \\
\leq & \ldots \\
\leq & \phi^{n}\left(d\left(x_{0}, x_{1}\right)\right)+\phi^{n+1}\left(d\left(x_{0}, x_{1}\right)\right) \\
& +\phi^{n+2}\left(d\left(x_{0}, x_{1}\right)\right)+\cdots+\phi^{n+2 m}\left(d\left(x_{0}, x_{1}\right)\right) \\
& \ldots m \\
&
\end{aligned}
$$


Letting $n \rightarrow \infty$, then, by using the condition $\left(\phi_{4}\right)$, we have

$$
\lim _{n \rightarrow \infty} d\left(x_{n}, x_{n+k}\right)=0
$$

Case (II). Suppose that $k>2$ and $k$ is even. Let $k=2 m, k \geq 1$. Then, by using the quadrilateral inequality, we also have

$$
\begin{aligned}
& d\left(x_{n}, x_{n+k}\right)=d\left(x_{n}, x_{n+2 m}\right) \\
& \leq d\left(x_{n}, x_{n+2}\right)+d\left(x_{n+2}, x_{n+4}\right)+d\left(x_{n+4}, x_{n+2 m}\right) \\
& \leq d\left(x_{n}, x_{n+2}\right)+d\left(x_{n+2}, x_{n+4}\right)+d\left(x_{n+4}, x_{n+6}\right) \\
& +\cdots+d\left(x_{n+2 m-2}, x_{n+2 m}\right) \\
& =d\left(f x_{n-1}, f x_{n+1}\right)+d\left(f x_{n+1}, f x_{n+3}\right) \\
& +d\left(f x_{n+3}, f x_{n+5}\right)+\cdots \\
& +d\left(f x_{n+2 m-3}, f x_{n+2 m-1}\right) \\
& \leq \alpha\left(x_{n-1}, x_{n+1}\right) d\left(f x_{n-1}, f x_{n+1}\right) \\
& +\alpha\left(x_{n+1}, x_{n+3}\right) d\left(f x_{n+1}, f x_{n+3}\right) \\
& +\alpha\left(x_{n+3}, x_{n+5}\right) d\left(f x_{n+3}, f x_{n+5}\right)+\cdots \\
& +\alpha\left(x_{n+2 m-3}, x_{n+2 m-1}\right) d\left(f x_{n+2 m-3}, f x_{n+2 m-1}\right) \\
& \leq \cdots \\
& \leq \phi^{n}\left(d\left(x_{0}, x_{2}\right)\right)+\phi^{n+2}\left(d\left(x_{0}, x_{2}\right)\right) \\
& +\phi^{n+4}\left(d\left(x_{0}, x_{2}\right)\right)+\cdots+\phi^{n+2 m}\left(d\left(x_{0}, x_{2}\right)\right) \\
& \leq \sum_{i=0}^{m} \phi^{n+2 i}\left(d\left(x_{0}, x_{2}\right)\right) \text {. }
\end{aligned}
$$

Letting $n \rightarrow \infty$. Then, by using the condition $\left(\phi_{4}\right)$, we have

$$
\lim _{n \rightarrow \infty} d\left(x_{n}, x_{n+k}\right)=0 \text {. }
$$

By above argument, we get that $\left\{x_{n}\right\}$ is a right-Cauchy sequence.

Analogously, we derive that the sequence $\left\{x_{n}\right\}$ is leftCauchy. Consequently, the sequence $\left\{x_{n}\right\}$ is Cauchy. Since $X$ is a complete g.q.m.s, there exists $u \in X$ such that

$$
\lim _{n \rightarrow \infty} d\left(x_{n}, u\right)=\lim _{n \rightarrow \infty} d\left(u, x_{n}\right)=0
$$

Step 4. We claim that $f$ has a periodic point in $X$. Suppose, on the contrary, that $f$ has no periodic point. Since $f$ is continuous, we obtain from (31) that

$$
\begin{aligned}
& \lim _{n \rightarrow \infty} d\left(x_{n+1}, f u\right)=\lim _{n \rightarrow \infty} d\left(f x_{n}, f u\right)=0, \\
& \lim _{n \rightarrow \infty} d\left(f u, x_{n+1}\right)=\lim _{n \rightarrow \infty} d\left(f u, f x_{n}\right)=0 .
\end{aligned}
$$

From (31) and (32), we get immediately that $\lim _{n \rightarrow \infty} f^{n} x_{0}=$ $\lim _{n \rightarrow \infty} f x_{n}=f u$. Due to Lemma 14, we conclude that $u=$ $f u$ which contradicts the assumption that $f$ has no periodic point. Therefore, there exists $u \in X$ such that $u=f^{p}(u)$ for some $p \in \mathbb{N}$. So $f$ has a periodic point in $X$.

Theorem 18. Let $(X, d)$ be a complete g.q.m.s, and let $\alpha: X \times$ $X \rightarrow \mathbb{R}^{+}$. Suppose $f$ is a $(\alpha-\phi-\psi)$-weaker Meir-Keeler contractive mapping which satisfies

(i) $f$ is $\alpha$-admissible;

(ii) there exists $x_{0} \in X$ such that $\alpha\left(x_{0}, f x_{0}\right) \geq 1$, $\alpha\left(f x_{0}, x_{0}\right) \geq 1$ and $\alpha\left(x_{0}, f^{2} x_{0}\right) \geq 1, \alpha\left(f^{2} x_{0}, x_{0}\right) \geq 1$;

(iii) if $\left\{x_{n}\right\}$ is a sequence in $X$ such that $\alpha\left(x_{n}, x_{n+1}\right) \geq 1$, $\alpha\left(x_{n+1}, x_{n}\right) \geq 1$ for all $n$ and $x_{n} \rightarrow x \in X$ as $n \rightarrow \infty$, then $\alpha\left(x_{n}, x\right) \geq 1, \alpha\left(x, x_{n}\right) \geq 1$ for all $n$.

Then $f$ has a periodic point in $X$.

Proof. Following the proof of Theorem 17, we know that the sequence $\left\{x_{n}\right\}$ defined by $x_{n+1}=f x_{n}$ for all $n \geq 0$, converges for some $u \in X$. From (31) and condition (iii), there exists a subsequence $\left\{x_{n(k)}\right\}$ of $\left\{x_{n}\right\}$ such that $\alpha\left(x_{n(k)}, u\right) \geq 1$ for all $k$. Applying (10), for all $k$, we get that

$$
\begin{aligned}
d\left(x_{n(k)+1}, f u\right)= & d\left(f x_{n(k)}, f u\right) \leq \alpha\left(x_{n(k)}, u\right) \\
& \times d\left(f x_{n(k)}, f u\right) \leq \phi\left(d\left(x_{n(k)}, u\right)\right), \\
d\left(f u, x_{n(k)+1}\right)= & d\left(f u, f x_{n(k)}\right) \leq \alpha\left(u, x_{n(k)}\right) \\
& \times d\left(f u, f x_{n(k)}\right) \leq \phi\left(u, d\left(x_{n(k)}\right)\right) .
\end{aligned}
$$

Letting $k \rightarrow \infty$ in the above equality, we find that

$$
\begin{aligned}
& d\left(x_{n(k)+1}, f u\right)=\lim _{k \rightarrow \infty} d\left(f x_{n(k)}, f u\right)=0, \\
& d\left(f u, x_{n(k)+1}\right)=\lim _{k \rightarrow \infty} d\left(f u, f x_{n(k)}\right)=0 .
\end{aligned}
$$

Therefoe, we have $\lim _{k \rightarrow \infty} f^{n(k)} x_{0}=\lim _{k \rightarrow \infty} f x_{n(k)}=f u$. Owing to Lemma 14, we conclude that $u=f u$ which contradicts the assumption that $f$ has no periodic point. Thus, there exists $u \in X$ such that $u=f^{p}(u)$ for some $p \in \mathbb{N}$. So $f$ has a periodic point in $X$.

\section{Periodic Points of Stronger Meir-Keeler Contractive Mappings}

In this section, we recall the notion of stronger Meir-Keeler function, as follows.

Definition 19. We call $\varphi:[0, \infty) \rightarrow[0,1)$ a stronger Meir-Keeler function if the function $\varphi$ satisfies the following condition:

$$
\begin{array}{r}
\forall \eta>0, \quad \exists \delta>0, \quad \exists \gamma_{\eta} \in[0,1), \quad \forall t \in[0, \infty), \\
\left(\eta \leq t<\delta+\eta \Longrightarrow \varphi(t)<\gamma_{\eta}\right) .
\end{array}
$$


And, we let the function $\varphi:[0, \infty) \rightarrow[0,1)$ satisfy the following conditions:

$\left(\varphi_{1}\right) \varphi:[0, \infty) \rightarrow[0,1)$ is a stronger Meir-Keeler function;

$\left(\varphi_{2}\right) \varphi(t)>0$ for $t>0$ and $\varphi(0)=0$.

Next, we introduce the notion of $(\alpha-\varphi)$-stronger MeirKeeler contractive mappings via the stronger Meir-Keeler function $\varphi$ and the $\alpha$-admissible mapping $\alpha$.

Definition 20. Let $(X, d)$ be a g.q.m.s, let $\alpha: X \times X \rightarrow \mathbb{R}^{+}$, and let $f: X \rightarrow X$ be a function satisfying

$$
\alpha(x, y) d(f x, f y) \leq \varphi(d(x, y)) d(x, y),
$$

for all $x, y \in X$. Then $f$ is said to be a $(\alpha-\varphi)$-stronger MeirKeeler contractive mapping.

We state two main periodic point theorms of $(\alpha-\varphi)$ stronger Meir-Keeler contractive mapping, as follows.

Theorem 21. Let $(X, d)$ be a complete g.q.m.s, and let $\alpha$ : $X \times X \rightarrow \mathbb{R}^{+}$. Suppose $f$ is a $(\alpha-\varphi)$-stronger Meir-Keeler contractive mapping which satisfies

(i) $f$ is $\alpha$-admissible;

(ii) there exists $x_{0} \in X$ such that $\alpha\left(x_{0}, f x_{0}\right) \geq 1$, $\alpha\left(f x_{0}, x_{0}\right) \geq 1$ and $\alpha\left(x_{0}, f^{2} x_{0}\right) \geq 1, \alpha\left(f^{2} x_{0}, x_{0}\right) \geq 1$;

(iii) $f$ is continuous.

Then $f$ has a periodic point in $X$.

Proof. Following the proof of Theorem 17, we obtained that

$$
\begin{aligned}
& \alpha\left(x_{n}, x_{n+1}\right) \geq 1, \quad \forall n=0,1, \ldots, \\
& \alpha\left(x_{n+1}, x_{n}\right) \geq 1, \quad \forall n=0,1, \ldots, \\
& \alpha\left(x_{n}, x_{n+2}\right) \geq 1, \quad \forall n=0,1, \ldots, \\
& \alpha\left(x_{n+2}, x_{n}\right) \geq 1, \quad \forall n=0,1, \ldots .
\end{aligned}
$$

Next, we prove that the sequence $\left\{x_{n}\right\}$ is Cauchy; that is, $\left\{x_{n}\right\}$ is both right-Cauchy and left-Cauchy.

Step 1. First, we will prove that

$$
\lim _{n \rightarrow \infty} d\left(x_{n}, x_{n+1}\right)=0 \text {. }
$$

Taking into account (36) and the definition of stronger MeirKeeler function $\varphi$, we have that, for each $n \in \mathbb{N}$,

$$
\begin{aligned}
d\left(x_{n}, x_{n+1}\right) & =d\left(f x_{n-1}, f x_{n}\right) \\
& \leq \alpha\left(x_{n-1}, x_{n}\right) d\left(f x_{n-1}, f x_{n}\right) \\
& \leq \varphi\left(d\left(x_{n-1}, x_{n}\right)\right) \cdot d\left(x_{n-1}, x_{n}\right) \\
& <d\left(x_{n-1}, x_{n}\right) .
\end{aligned}
$$

Thus the sequence $\left\{d\left(x_{n}, x_{n+1}\right)\right\}$ is decreasing and bounded below and hence it is convergent. Let $\lim _{n \rightarrow \infty} d\left(x_{n}, x_{n+1}\right)=$ $\eta \geq 0$. Then there exists $n_{0} \in \mathbb{N}$ and $\delta>0$ such that for all $n \in \mathbb{N}$ with $n \geq n_{0}$

$$
\eta \leq d\left(x_{n}, x_{n+1}\right)<\eta+\delta .
$$

Taking into account (40) and the definition of stronger MeirKeeler function $\varphi$, corresponding to $\eta$ use, there exists $\gamma_{\eta} \in$ $[0,1)$ such that

$$
\varphi\left(d\left(x_{n}, x_{n+1}\right)\right)<\gamma_{\eta} \quad \forall n \geq n_{0}
$$

Thus, we can deduce that for each $n \in \mathbb{N}$ with $n \geq n_{0}+1$

$$
\begin{aligned}
d\left(x_{n}, x_{n+1}\right) & =d\left(f x_{n-1}, f x_{n}\right) \\
& \leq \alpha\left(x_{n-1}, x_{n}\right) d\left(f x_{n-1}, f x_{n}\right) \\
& \leq \varphi\left(d\left(x_{n-1}, x_{n}\right)\right) \cdot d\left(x_{n-1}, x_{n}\right) \\
& <\gamma_{\eta} \cdot d\left(x_{n-1}, x_{n}\right)
\end{aligned}
$$

and so

$$
\begin{aligned}
d\left(x_{n}, x_{n+1}\right) & <\gamma_{\eta} \cdot d\left(x_{n-1}, x_{n}\right) \\
& <\gamma_{\eta}^{2} \cdot d\left(x_{n-2}, x_{n-1}\right) \\
& <\cdots \\
& <\gamma_{\eta}^{n-n_{0}} \cdot d\left(x_{n_{0}}, x_{n_{0}+1}\right) .
\end{aligned}
$$

Since $\gamma_{\eta} \in[0,1)$, we get

$$
\lim _{n \rightarrow \infty} d\left(x_{n}, x_{n+1}\right)=0
$$

Step 2. We will prove that

$$
\lim _{n \rightarrow \infty} d\left(x_{n}, x_{n+2}\right)=0
$$

Taking into account (36) and the definition of stronger MeirKeeler function $\varphi$, we have that for each $n \in \mathbb{N}$

$$
\begin{aligned}
d\left(x_{n}, x_{n+2}\right) & =d\left(f x_{n-1}, f x_{n+1}\right) \\
& \leq \alpha\left(x_{n-1}, x_{n+1}\right) d\left(f x_{n-1}, f x_{n+1}\right) \\
& \leq \varphi\left(d\left(x_{n-1}, x_{n+1}\right)\right) \cdot d\left(x_{n-1}, x_{n+1}\right) \\
& <d\left(x_{n-1}, x_{n+1}\right) .
\end{aligned}
$$

Thus the sequence $\left\{d\left(x_{n}, x_{n+2}\right)\right\}$ is decreasing and bounded below and hence it is convergent. By the same above proof process of Step 1, we also conclude that

$$
\lim _{n \rightarrow \infty} d\left(x_{n}, x_{n+2}\right)=0
$$


Step 3. We will prove that the sequence $\left\{x_{n}\right\}$ is right-Cauchy by standard technique. For this purpose, it is sufficient to examine two cases.

Case (I). Suppose that $k>2$ and $k$ is odd. Let $k=2 m+1$, $k \geq 1$. Then, by using the quadrilateral inequality, we have

$$
\begin{aligned}
& d\left(x_{n}, x_{n+k}\right)= d\left(x_{n}, x_{n+2 m+1}\right) \\
& \leq d\left(x_{n}, x_{n+1}\right)+d\left(x_{n+1}, x_{n+2}\right) \\
&+d\left(x_{n+2}, x_{n+2 m+1}\right) \\
& \leq d\left(x_{n}, x_{n+1}\right)+d\left(x_{n+1}, x_{n+2}\right) \\
&+d\left(x_{n+2}, x_{n+3}\right) \\
&+\cdots+d\left(x_{n+2 m}, x_{n+2 m+1}\right) \\
&= d\left(f x_{n-1}, f x_{n}\right)+d\left(f x_{n}, f x_{n+1}\right) \\
&+d\left(f x_{n+1}, f x_{n+2}\right)+\cdots+d\left(f x_{n+2 m-1}, x_{n+2 m}\right) \\
& \leq \alpha\left(x_{n-1}, x_{n}\right) d\left(f x_{n-1}, f x_{n}\right) \\
&+\alpha\left(x_{n}, x_{n+1}\right) d\left(f x_{n}, f x_{n+1}\right) \\
&+\alpha\left(x_{n+1}, x_{n+2}\right) d\left(f x_{n+1}, f x_{n+2}\right) \\
&+\cdots+\alpha\left(x_{n+2 m-1}, x_{n+2 m}\right) d\left(f x_{n+2 m-1}, x_{n+2 m}\right) \\
& \leq \cdots \\
& \leq \gamma_{\eta}^{n-n_{0}} \cdot d\left(x_{n_{0}}, x_{n_{0}+1}\right)+\gamma_{\eta}^{n-n_{0}+1} \cdot d\left(x_{n_{0}}, x_{n_{0}+1}\right) \\
&+\gamma_{\eta}^{n-n_{0}+2} \cdot d\left(x_{n_{0}}, x_{n_{0}+1}\right)+\cdots \\
& i=0 \\
& \gamma_{\eta} n \\
& n-n_{0}+i \\
&
\end{aligned}
$$

Letting $n \rightarrow \infty$, then, we have

$$
\lim _{n \rightarrow \infty} d\left(x_{n}, x_{n+k}\right)=0 .
$$

Case (II). Suppose that $k>2$ and $k$ is even. Let $k=2 m, k \geq 1$. Then, by using the quadrilateral inequality, we also have

$$
\begin{aligned}
d\left(x_{n}, x_{n+k}\right)= & d\left(x_{n}, x_{n+2 m}\right) \\
\leq & d\left(x_{n}, x_{n+2}\right)+d\left(x_{n+2}, x_{n+4}\right) \\
& +d\left(x_{n+4}, x_{n+2 m}\right) \\
\leq & d\left(x_{n}, x_{n+2}\right)+d\left(x_{n+2}, x_{n+4}\right) \\
& +d\left(x_{n+4}, x_{n+6}\right)+\cdots \\
& +d\left(x_{n+2 m-2}, x_{n+2 m}\right)
\end{aligned}
$$

$$
\begin{aligned}
= & d\left(f x_{n-1}, f x_{n+1}\right)+d\left(f x_{n+1}, f x_{n+3}\right) \\
& +d\left(f x_{n+3}, f x_{n+5}\right)+\cdots \\
& +d\left(f x_{n+2 m-3}, f x_{n+2 m-1}\right) \\
\leq & \alpha\left(x_{n-1}, x_{n+1}\right) d\left(f x_{n-1}, f x_{n+1}\right) \\
& +\alpha\left(x_{n+1}, x_{n+3}\right) d\left(f x_{n+1}, f x_{n+3}\right) \\
& +\alpha\left(x_{n+3}, x_{n+5}\right) d\left(f x_{n+3}, f x_{n+5}\right)+\cdots \\
& +\alpha\left(x_{n+2 m-3}, x_{n+2 m-1}\right) d\left(f x_{n+2 m-3}, f x_{n+2 m-1}\right) \\
\leq & \cdots \\
\leq & \gamma_{\eta}^{n-n_{0}} \cdot d\left(x_{n_{0}}, x_{n_{0}+2}\right)+\gamma_{\eta}^{n-n_{0}+2} \cdot d\left(x_{n_{0}}, x_{n_{0}+2}\right) \\
& +\gamma_{\eta}^{n-n_{0}+4} \cdot d\left(x_{n_{0}}, x_{n_{0}+2}\right)+\cdots \\
& +\gamma_{\eta}^{n-n_{0}+2 m} \cdot d\left(x_{n_{0}}, x_{n_{0}+2}\right) \\
\leq & \sum_{i=0}^{m} \gamma_{\eta}^{n-n_{0}+2 i} \cdot d\left(x_{n_{0}}, x_{n_{0}+2}\right) .
\end{aligned}
$$

Letting $n \rightarrow \infty$, then, by using the condition $\phi_{4}$, we have

$$
\lim _{n \rightarrow \infty} d\left(x_{n}, x_{n+k}\right)=0
$$

By above argument, we get that $\left\{x_{n}\right\}$ is a right-Cauchy sequence.

Analogously, we derive that the sequence $\left\{x_{n}\right\}$ is leftCauchy. Consequently, the sequence $\left\{x_{n}\right\}$ is Cauchy.

Since $X$ is a complete g.q.m.s, there exists $u \in X$ such that

$$
\lim _{n \rightarrow \infty} d\left(x_{n}, u\right)=\lim _{n \rightarrow \infty} d\left(u, x_{n}\right)=0
$$

Step 4. We claim that $f$ has a periodic point in $X$. Suppose, on the contrary, that $f$ has no periodic point. Since $f$ is continuous, we obtain from (52) that

$$
\begin{aligned}
& \lim _{n \rightarrow \infty} d\left(x_{n+1}, f u\right)=\lim _{n \rightarrow \infty} d\left(f x_{n}, f u\right)=0, \\
& \lim _{n \rightarrow \infty} d\left(f u, x_{n+1}\right)=\lim _{n \rightarrow \infty} d\left(f u, f x_{n}\right)=0 .
\end{aligned}
$$

From (52) and (53), we get immediately that $\lim _{n \rightarrow \infty} f^{n} x_{0}=$ $\lim _{n \rightarrow \infty} f x_{n}=f u$. Regarding Lemma 14, we deduce that $u=$ $f u$ which contradicts the assumption that $f$ has no periodic point. So, there exists $u \in X$ such that $u=f^{p}(u)$ for some $p \in \mathbb{N}$. So $f$ has a periodic point in $X$.

Apply Theorems 18 and 21, and we can easily deduce the following theorem.

Theorem 22. Let $(X, d)$ be a complete g.q.m.s, and let $\alpha$ : $X \times X \rightarrow \mathbb{R}^{+}$. Suppose $f$ is a $(\alpha-\varphi)$-stronger Meir-Keeler contractive mapping which satisfies

(i) $f$ is $\alpha$-admissible; 
(ii) there exists $x_{0} \in X$ such that $\alpha\left(x_{0}, f x_{0}\right) \geq 1$, $\alpha\left(f x_{0}, x_{0}\right) \geq 1$ and $\alpha\left(x_{0}, f^{2} x_{0}\right) \geq 1, \alpha\left(f^{2} x_{0}, x_{0}\right) \geq 1$;

(iii) if $\left\{x_{n}\right\}$ is a sequence in $X$ such that $\alpha\left(x_{n}, x_{n+1}\right) \geq 1$, $\alpha\left(x_{n+1}, x_{n}\right) \geq 1$ for all $n$ and $x_{n} \rightarrow x \in X$ as $n \rightarrow \infty$, then $\alpha\left(x_{n}, x\right) \geq 1, \alpha\left(x, x_{n}\right) \geq 1$ for all $n$.

Then $f$ has a periodic point in $X$.

\section{Conflict of Interests}

The authors declare that they have no competing interests.

\section{Authors' Contribution}

All authors contributed equally and significantly to writing this paper. All authors read and approved the final paper.

\section{Acknowledgment}

The authors thank the anonymous referees for their remarkable comments, suggestions, and ideas that helped to improve this paper.

\section{References}

[1] I.-J. Lin, C.-M. Chen, and E. Karapınar, "Periodic points of weaker meir-keeler contractive mappings on generalized quasimetric spaces," Abstract and Applied Analysis, vol. 2014, Article ID 490450, 6 pages, 2014.

[2] A. Branciari, "A fixed point theorem of Banach-Caccioppoli type on a class of generalized metric spaces," Publicationes Mathematicae Debrecen, vol. 57, no. 1-2, pp. 31-37, 2000.

[3] T. Suzuki, "Generalized metric spaces do not have the compatible topology," Abstract and Applied Analysis, vol. 2014, Article ID 458098, 5 pages, 2014.

[4] E. Karapinar and H. Lakzian, " $(\alpha-\psi)$-contractive mappings on generalized quasi-metric spaces," Journal of Function Spaces, vol. 2014, Article ID 914398, 7 pages, 2014.

[5] M. Jleli and B. Samet, "The Kannan's fixed point theorem in a cone rectangular metric space," Journal of Nonlinear Science and its Applications, vol. 2, no. 3, pp. 161-167, 2009.

[6] W. A. Kirk and N. Shahzad, "Generalized metrics and Caristi's theorem," Fixed Point Theory and Applications, vol. 2013, article 129, 9 pages, 2013.

[7] E. Karapinar, "Discussion on $(\alpha, \psi)$ contractions on generalized metric spaces," Abstract and Applied Analysis, vol. 2014, Article ID 962784, 7 pages, 2014.

[8] Z. Kadeburg and S. Radenovic, "On generalized metric spaces: a survey," TWMS Journal of Pure and Applied Mathematics, vol. 5, no. 1, pp. 3-13, 2014.

[9] H. Aydi, E. Karapınar, and B. Samet, "Fixed points for generalized $(\alpha, \psi)$-contractions on generalized metric spaces," Journal of Inequalities and Applications, vol. 2014, article 229, 2014.

[10] I. R. Sarma, J. M. Rao, and S. S. Rao, "Contractions over generalized metric spaces," Journal of Nonlinear Science and Its Applications, vol. 2, no. 3, pp. 180-182, 2009.

[11] A. Azam and M. Arshad, "Kannan fixed point theorem on generalized metric spaces," Journal of Nonlinear Sciences and Its Applications, vol. 1, no. 1, pp. 45-48, 2008.
[12] P. Das, "A fixed point theorem on a class of generalized metric spaces," Korean Journal of Mathematical Sciences, vol. 9, pp. 2933, 2002.

[13] I. M. Erhan, E. Karapinar, and T. Sekulic, "Fixed points of $(\psi, \varphi)$ contractions on rectangular metric spaces," Fixed Point Theory and Applications, vol. 2012, article 138, 2012.

[14] D. Mihet, "On Kannan fixed point principle in generalized metric spaces," Journal of Nonlinear Science and Its Applications, vol. 2, no. 2, pp. 92-96, 2009.

[15] B. Samet, "A fixed point theorem in a generalized metric space for mappings satisfying a contractive condition of integral type," International Journal of Mathematical Analysis, vol. 6, no. 3, pp. 1265-1271, 2009.

[16] B. Samet, "Discussion on: a fixed point theorem of BanachCaccioppoli type on a class of generalized metric spaces," Publicationes Mathematicae Debrecen, vol. 76, no. 4, pp. 493494, 2010.

[17] H. Lakzian and B. Samet, "Fixed points for $(\psi, \varphi)$-weakly contractive mappings in generalized metric spaces," Applied Mathematics Letters, vol. 25, no. 5, pp. 902-906, 2012.

[18] A. Meir and E. Keeler, "A theorem on contraction mappings," Journal of Mathematical Analysis and Applications, vol. 28, pp. 326-329, 1969.

[19] B. Samet, C. Vetro, and P. Vetro, "Fixed point theorems for $\alpha-\psi$-contractive type mappings," Nonlinear Analysis: Theory, Methods \& Applications, vol. 75, no. 4, pp. 2154-2165, 2012. 


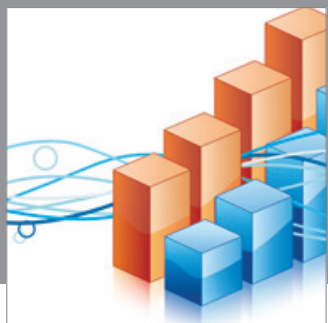

Advances in

Operations Research

mansans

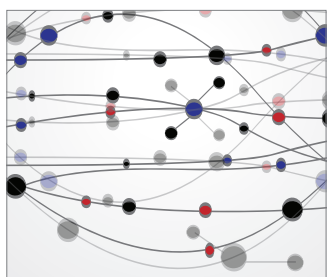

The Scientific World Journal
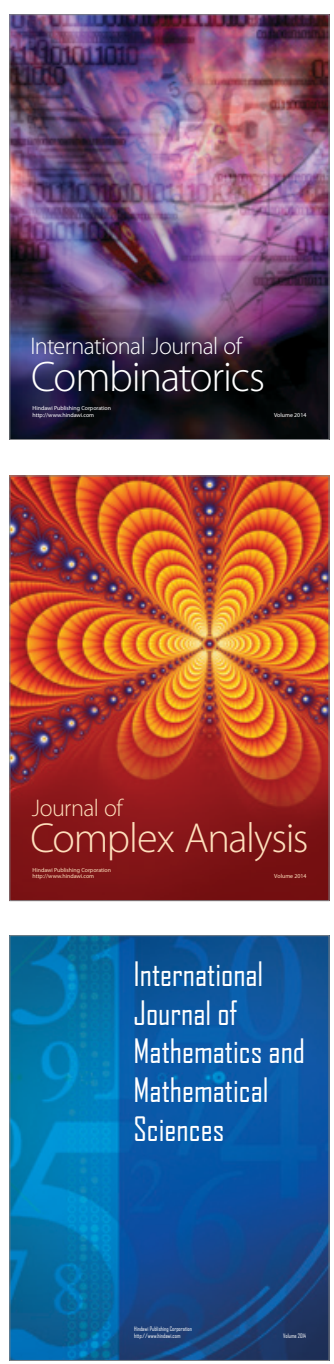
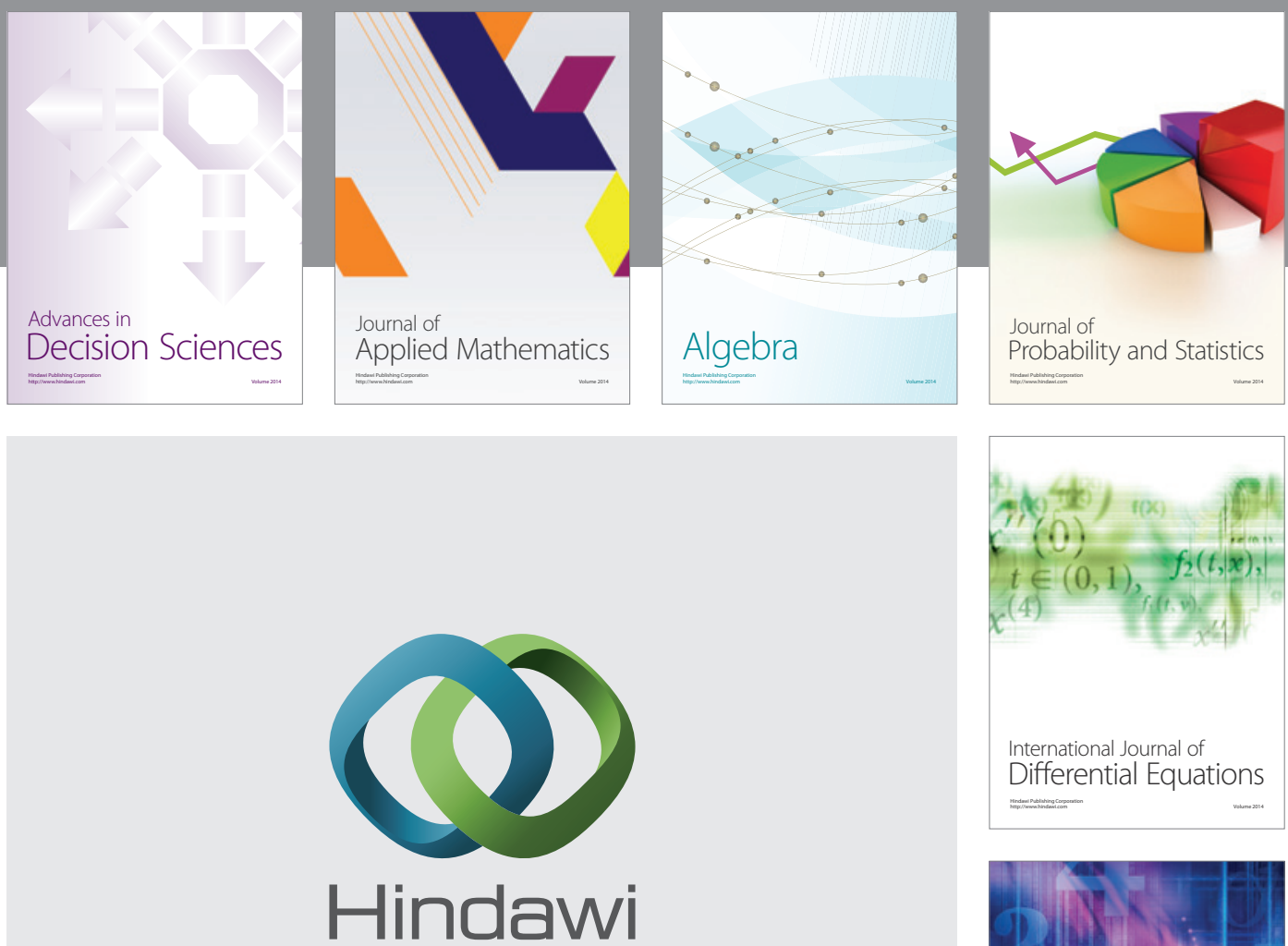

Submit your manuscripts at http://www.hindawi.com
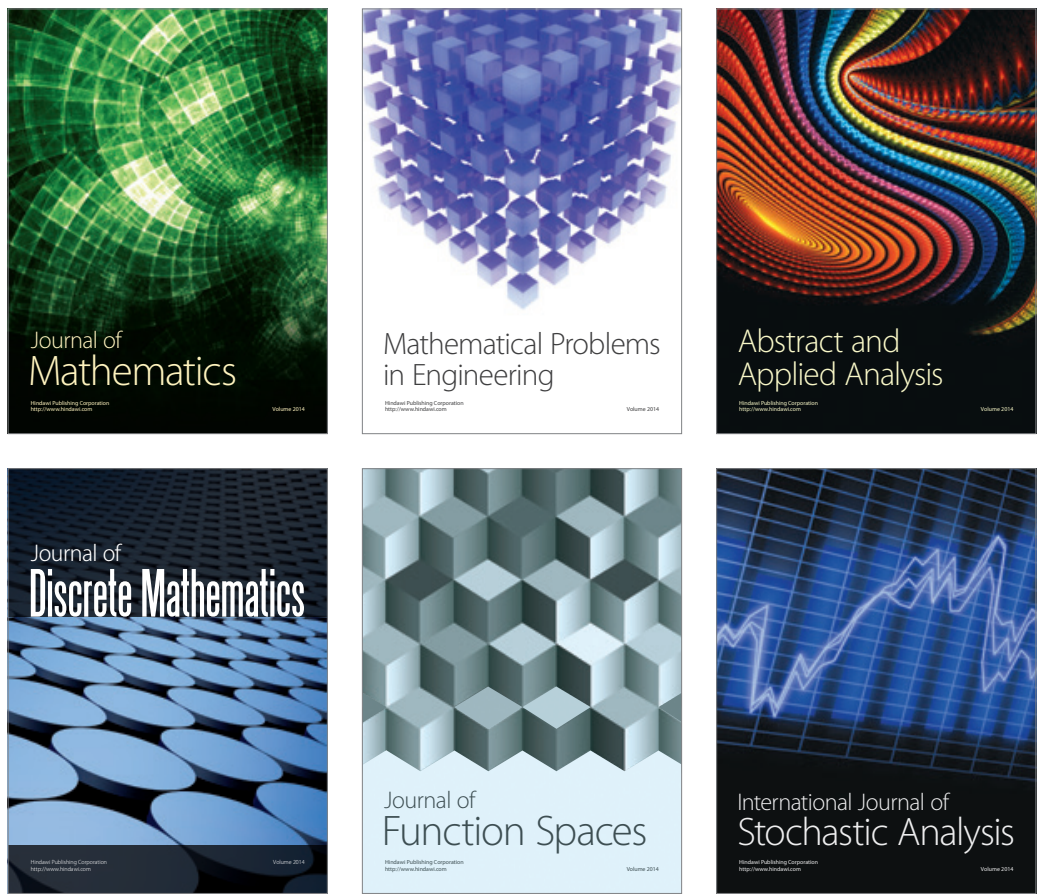

Journal of

Function Spaces

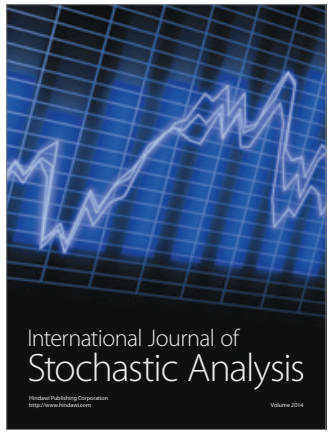

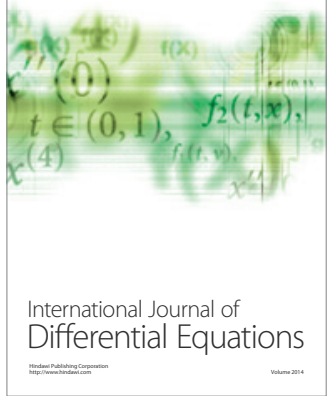
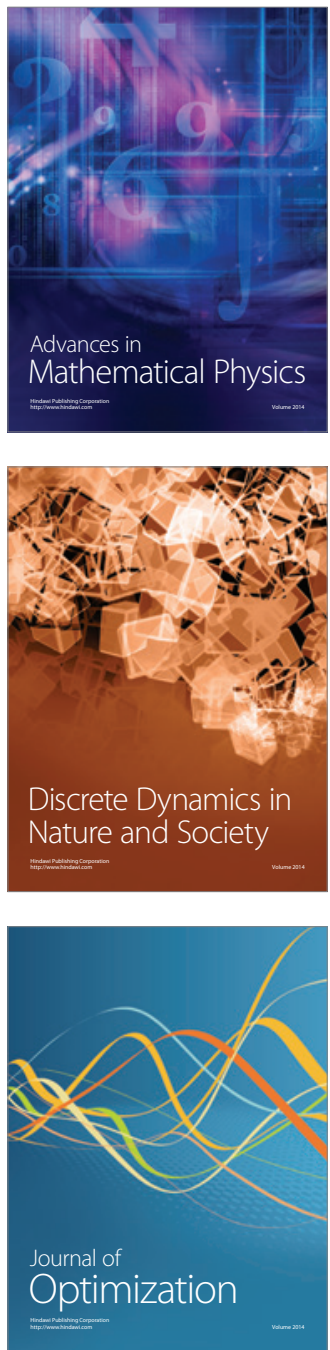